\title{
Maden ocaklarında insansız hava aracı kullanımı: örnek bir saha çalışması
}

\author{
Mete KUN ${ }^{1, *}$, Berk ÖZCAN² \\ ${ }^{1}$ Dokuz Eylül Üniversitesi, Müh. Fakültesi, Maden Mühendisliği Bölümü, İzmir. \\ ${ }^{2}$ Dokuz Eylül Üniversitesi, Fen Bilimleri Enstitüsü, İzmir. \\ Geliş Tarihi (Received Date): 27.11.2018 \\ Kabul Tarihi (Accepted Date): 22.03.2019
}

\section{Özet}

Günümüzde boyutu hızla küçülen ve özellikleri artan kamera, batarya ve küresel konumlama sistemleri sayesinde insansız hava araçlart (IHA) ve modern fotogrametrik metotları kullanan görsel işleme yazllımları hızla gelişmektedir. IHA destekli görsel işleme yazllımlarl endüstrinin birçok alanında kendine yer bulmuş ve madencilik alanında $d a$, süregelen klasik metotları geliştirmeye başlamıştır. Özellikle maden sahalarının geniş alanlar kaplaması, ölçümlerinin uzun zaman alması ve maliyetli olması, IHA 'lar ile birlikte fotogrametrik görsel işleme yazılılarının kullanımını ihtiyaç haline getirmektedir. Hazırlanan çalışma, örnek bir maden sahasında gerçekleşen hacim, alan ve kabarma faktörü gibi, özellikle açık işletme madenciliğinde planlama ve hesaplamalarda kullanılan bazı verilerin, IHA kullanımı ile hızl ve güvenilir bir biçimde eldesini konu almaktadır. Çalışma sonucunda, ele alınan sahada klasik metotlarla yapilan hesaplamalar ile IHA'lar ile elde edilen verilerin, uyumlu ve birbirlerine oldukça yakın değerler verdiği saptanmış ve sonuçlar yorumlanmıştır.

Anahtar kelimeler: Insansız hava aracı, açık işletme madenciliği, hacim hesabı, kabarma faktörü.

\section{Usage of unmanned aircraft in mining quarries: a sample field study}

\begin{abstract}
Nowadays, thanks to the rapidly shrinking and increasingly featured camera, battery

\footnotetext{
*Mete KUN, mete.kun@deu.edu.tr, http://orcid.org/0000-0002-2042-3401

Berk ÖZCAN, berk.ozcan@ogr.deu.edu.tr, https://orcid.org/0000-0002-3560-0597
} and global positioning systems, one of the premier of these fields is visualprocessing 
software using modern photogrammetric methods supported by unmanned aerial vehicles (UAVS). UAV supported visual processing software has found itself in many areas and has begun to develop ongoing methods in the field of mining. Especially the large area coverage of mine sites, their long time taking and costly measurements make the use of photogrammetric image processing software a necessity. In this study; fast and reliable use of unmanned aerial vehicles, such as in-situ volume, area and swell factor, which are used in planning and calculations, especially in open pit mining, taking place in a sample mine excavation area. As a result of the study, the data both obtained by the convensional methods and with the UAVS in the study area were found to be compatible and very close to each other.

Keywords: Unmanned aerial vehicles, open pit mining, volume, swell factor.

\section{Giriş}

2000'li yılların başından itibaren kullanımı ve teknolojileri hızla gelişen insansız hava araçlarının (İHA) dünya genelinde, özellikle uzaktan algılama ve yerbilimleri alanlarında kullanımı giderek artmıştır. İHA'lar ile elde edilen yüksek çözünürlüklü görseller, bilgisayar destekli görsel işleme yazılımlarının da gelişimini desteklemiş ve daha ayrıntılı sayısal arazi modeli (SAM), sayısal yüzey modeli (SYM) ve nokta bulutu üretimini mümkün kılmıştır.

İHA yardımıyla gerçekleştirilen çalışmalar yersel fotogrametrideki hassasiyete yaklaşmakta ve çalışmaları kısa sürede tamamlayabilmesi açısından birçok farklı alanda uygulanma olanağı bulmaktadır [1]. Son 10 yıllık süreçte bir çok araştırmacı; heyelanların izlenmesi ve yüksek çözünürlüklü görüntülerinin elde edilmesinde [2], orman arazilerinin yüzeylerin çıkarılmasında ve bitki gelişiminin incelenmesinde [3], İHA görüntülerinin haritalama çalışmalarında kullanılmasında [4], İHA'ların geniş ölçekli afet çalışmalarında iletişim sağlamasında [5], yüksek hassasiyetli sayısal yükseklik modeli üretilmesi ve ormancılık alanlarında kullanılmasında [6], tarihi eserlerin ve alanların röleve ve modellerinin çıkartılması [7] gibi pek çok disiplinde etkin çalışmalar yapılmakta ve olumlu sonuçlar elde edilmektedir. Ayrıca Tekirdağ yöresinde, yaklaşık 12 adet farklı ocağın incelendiği çalışmada, İHA'lar ile alınan görüntülerin işlenmesi ile elde edilen sonuçların başarısı ve uydu fotoğraflarına göre üstünlükleri belirtilmiştir [8]. İnsansız hava araçlarının başarısını ve maden sahalarında kullanımını ele alan bir diğer çalışmada ise İHA fotogrametrisinin, açık maden işletmelerinde kullanımının gerek emek-zaman gerek iş güvenliği gerekse maliyet açısından büyük avantajlar sağladığı net olarak ortaya konulmuştur [9].

Madencilik endüstrisinde de özellikle açık işletme maden planlarının her aşamasında, imalat haritalarının çıkarılmasında, basamak geometrilerinin ve stabilitesinin kontrolünden, saha rehabilitasyon çalışmalarına kadar bir madencilik girişiminin her aşamasında kullanılan İHA'lar, son zamanlarda sahalardaki hassas ve kısa zamanlı alan ve hacim ölçümlerinin yapılmasında aktif halde kullanılmaktadır. Hacim ve alanlar hem yerinde hem de stok sahasında ölçülebilmekte bu sayede nakliye planlaması için kullanılacak miktar, kabarma faktörü ve/veya sıkışma faktörü gibi parametreler sağlıklı şekilde ortaya koyulabilmektedir. 
$\mathrm{Bu}$ çalışmada üzerinde durulduğu gibi, insansız hava araçlarının, uygun yazılımlar ile madencilik operasyonlarında ya da herhangi bir kazı alanında kullanımı, geleneksel yöntemlerden farklı olarak birkaç yüz nokta ile değil, milyonlarca noktalık yoğun nokta bulutlarıyla oluşturulabilmektedir. Bu sayede alınan ölçüm ve belirlenen hacimsel veriler çok daha hassas tamamlanmakta ve elde edilen verilerin hata payları da bir o kadar düşük tutulmaktadır. İHA'ların önceden öngörülebilen uçuş planına bağlı olarak otomatik uçabilmesi, alınan ölçümlerdeki insan hatalarını en aza indirmekte ayrıca doğru açı ve sistematik görsel eldesi, geniş çalışma alanlarında dahi hassas ölçümleri de mümkün kılmaktadır.

\section{Materyal ve metod}

Alan çalışmasında kullanılan İHA, Sivil Havacılık Genel Müdürlüğü (SHGM) nün yayınladığı ve Tablo 1'de gösterildiği gibi azami kalkış ağırlığı 1388 gram olan, İHA-0 sinıfına dahildir [11].

1 inçlik 20 MP CMOS sensörü ve 35 mm'lik odak uzaklığ 1 olan tek parça lensi ile 5472 × 3648 pixel çözünürlükle JPG ve RAW formatında görsel eldesi yapabilen 4 pervaneli İHA, havada tek bir batarya ile 27 dakika kalabilmektedir [10]. Çalışma kapsamında 2 yedek batarya ile kullanılan cihazın, değişmeyen hava koşullarında stabil olarak çalışması ve dolayısı ile aynı koşullarda veri üretmesi sağlanmıştır (Şekil 1).
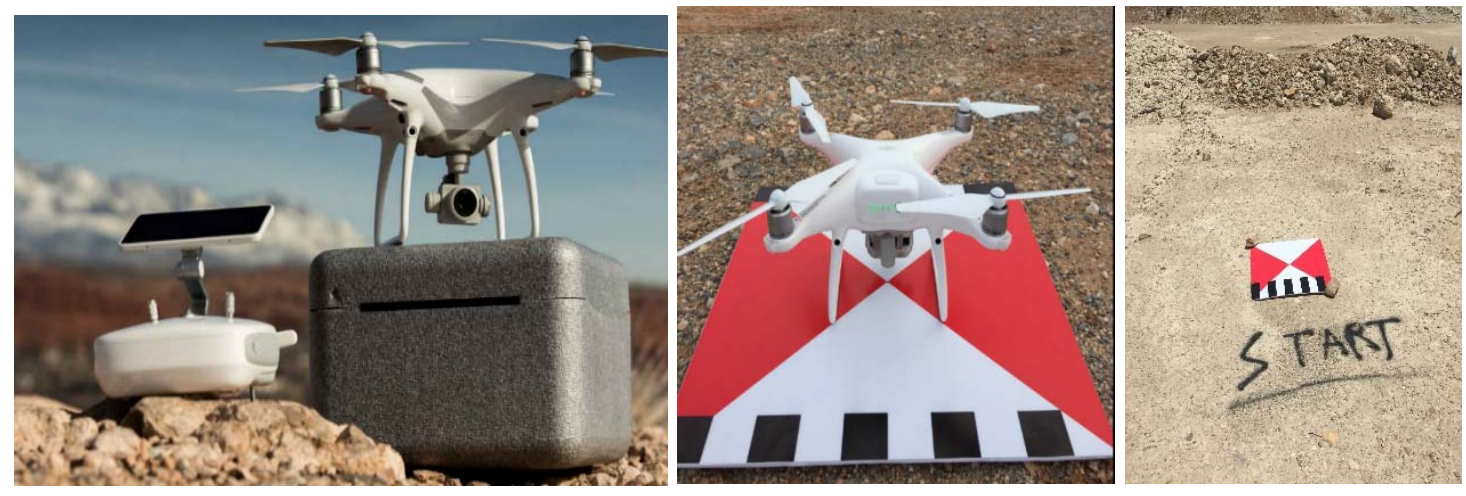

Şekil 1. Saha çalışmalarında kullanılan İHA ve alan kontrol noktası örneği.

Tablo 1. İnsansız hava araçları sınıfları [11].

\begin{tabular}{|c|c|}
\hline Sınıf Kodu & Sınıf Özelliği \\
\hline İHA-0 & Azami kalkış ağırlığı 500 gr (dâhil) - 4kg aralığında olan İHA'lar \\
\hline İHA-1 & Azami kalkış ağırlığı 4 kg (dâhil) - 25 kg aralığında olan İHA'lar \\
\hline İHA-2 & Azami kalkış ağırlığı $25 \mathrm{~kg}$ (dâhil) - $150 \mathrm{~kg}$ aralığında olan İHA'lar \\
\hline İHA-3 & Azami kalkış ağırlığı $150 \mathrm{~kg}$ (dâhil) ve daha fazla olan İHA'lar \\
\hline
\end{tabular}

Ek olarak GLONASS ve GPS uydu desteği olan konumlandırma modülü, $10 \mathrm{~m} / \mathrm{s}^{\prime}$ lik rüzgar direnci, $7 \mathrm{~km}$ yatay, $500 \mathrm{~m}$ dikey kumanda kontrol mesafesi, $0-40 \mathrm{C}^{\circ}$ 'lik 1s1 tölaransı, 2.4 ve $5.8 \mathrm{Ghz}$ frekans kanalları arasında ihtiyaç durumunda geçiş 
yapabilmesi ve ön, arka, yan ve alt sensörleri sayesinde, maden sahalarında kullanılmak üzere bu çalışma için tercih edilmiştir.

\subsection{Küresel konumlama sistemi}

Çalışma içerisinde kullanılan İHA' ya ek olarak, konumlandırma sistemi olarak, Ashtech Promark 800 GNSS cihazı kullanılmıştır. Üretici firmanın Z-Blade teknolojisi ile GNSS performansı optimize edilmiş sistem 120 adet GNSS kanalına sahiptir. Gerçek zamanlı konumlamada yatayda en iyi $10 \mathrm{~mm} \pm 1,0 \mathrm{ppm}$ ve dikeyde $20 \mathrm{~mm} \pm 1,0 \mathrm{pmm}$. hassasiyetle çalışmakta olan sistem $20 \mathrm{~Hz}$ 'e kadar gerçek zamanlı ham data ve konum çıktısı verebilmektedir [12].

\subsection{Kullanılan fotogrametri yazılımı ve yazılımın android uygulaması}

İHA'lar için geliştirilen ve kullanım alanı bulan birçok farklı görüntü işleme yazılımı bulunmaktadır. Çalışmada kullanılan Pix4D capture uygulaması, çalışma yapılacak alanda uçuş planını ve uçuş öncesinde kapsamlı bir biçimde ön izlemeyi sağlamaktadır. $\mathrm{Bu}$ yazılım sayesinde verilerin işleneceği ana yazılıma görseller doğru, sabit ve üst üste bindirme oranlarıyla aktarılır. Uygulama sayesinde uçuşa başlanmadan üst üste bindirme oranları (ön ve yan olarak), uçuş yüksekliği, uçuş süresi, uçuş güzergahı, kalkış ve iniş noktaları belirlenebilir.

Ayrıca çalışma içerisinde, İHA ile eldesi sağlanan görselleri girdi olarak kullanan yazılım SAM, SYM, ortofoto, yoğun nokta bulutu, indeks haritası, üç boyutlu (3B) model, kontur haritası gibi çıtılar veren Pix4D mapper yazılımlarından da yararlanılmıştır. Tercih edilen yazılım, diğer fotogrametrik yazılımlardan kendine özgü algoritması, koordinatlı veya koordinatsız çalışabilmesi, nokta üretiminde ikiden fazla görseli aynı anda kullanabilmesi ve çalışma alanının genişliği göz önüne alındığında, ayrilmaktadir.

\subsection{Metodoloji}

Görsel işleme yazılımlarından en verimli şekilde yararlanmak amacıyla çalışma yapılacak arazinin detaylı olarak incelenmesi kritik önem taşımaktadır. İHA havalanmadan önce alanın içeriğine göre, alan içerisinde yerüstü kontrol noktaları belirlenmelidir. Görsellerin işlenmesi aşamasında kullanılacak olan bu yerüstü kontrol noktaları, hata payını azaltmak ve görüntüler arası bağlantıyı güçlendirmek için kullanılmaktadır. Ayrıca alan içerisinde bulunan belirgin kayaçları ve binaları önceden belirlemek ve uçuş planını bu noktaları kapsayacak şekilde gerçekleştirmek, çıkacak olan nihai sonucun hata payını önemli ölçüde azaltmaktadır. Alan büyüklüğüne ve yapısına (özellikle nehir veya göl bulunuyorsa) göre fotoğrafların üst üste bindirme oranının tespiti ve fotoğraf çekme sıklığının ayarlanması da, çıkacak sonuç için hayati önem taşımaktadır.

Uçuş planının dizaynı için, çalışma yapılacak alanın büyüklügüüne istenen detay seviyesine bağlı olarak seçilir. İHA ile uzaktan bağlantı kuran yer istasyonu (tablet veya akıllı telefon) üzerinde kurulu olan yardımcı yazılım aracılığı ile uçuş planı ayarları toplanan bilgiler ışığında belirlenir. Bu aşamada yapılacak olan uçuşun kalitesi, toplanan bilgiler kapsamında oluşturulan ayarlar ile belirlenmelidir. Şekil 2'de gösterildiği gibi fotogrametri yazılımının üç temel aşaması bulunmaktadır. İlk aşama olan ilksel işleme aşamasında yazılım İHA ile eldesi sağlanan görsellerin içine gömülü olan içsel ve dışsal kamera verilerini çıkarır ve düzenler. Işın demetinin de şekillendiği bu aşamada öncü ve seyrek bir nokta bulutu oluşturulur. 
İkinci aşamada ise nokta bulutu yoğunlaştırılması ve filtrelenmesi yapılır. Yoğun nokta bulutunun şekillendiği bu aşamada üçgenleme veya nokta bulutu sinıflandırması yapılması isteğe bağlıdır.

Üçüncü ve son aşamada SYM, SAM ve ortofoto oluşumu yapılmaktadır. Ayrıca kontur haritası ve Google Maps için koordinatlı ortofoto oluşumu yapılabilir. Ayrıca yine jeoreferanslama ve bütünlüklü model eldesi de bu aşamada tamamlanır. Kullanılan yazılıma bağlı olarak katı yüzey modeli veya nokta bulutu oluşturulur. Hizalanmış nokta bulutları ile sonunda bir SAM (Sayısal Arazi Modeli) ve orto-görüntü üretmek mümkündür [13].

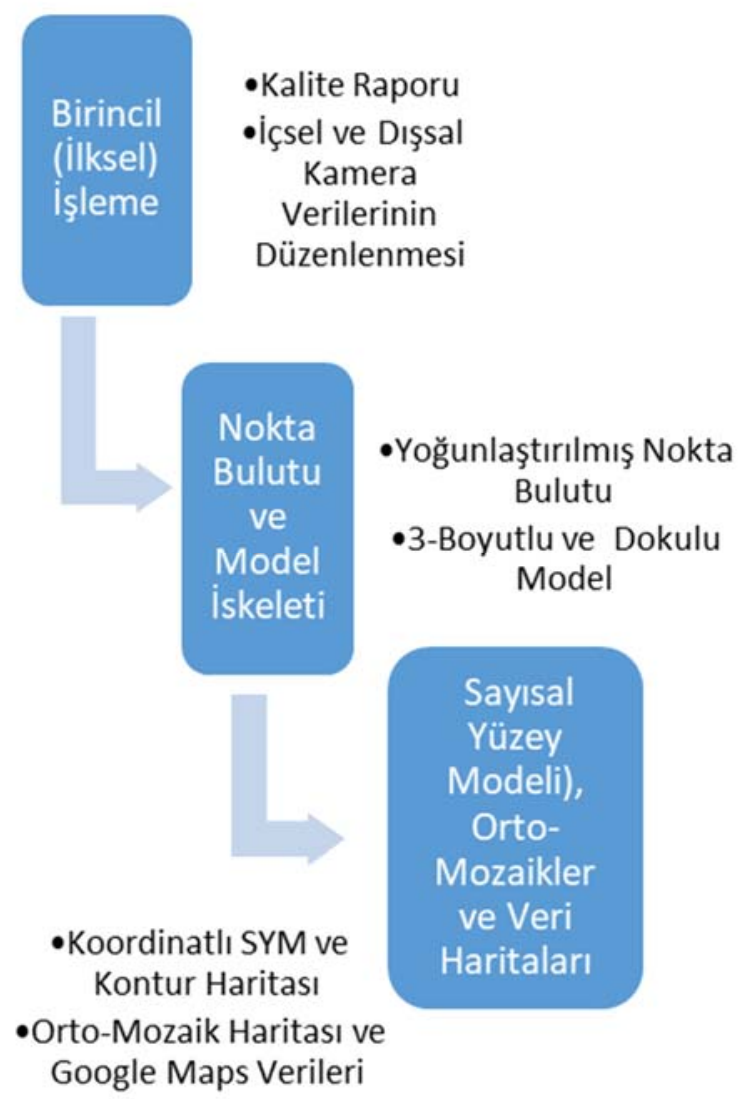

Şekil 2. Fotogrametri yazılımının çalışma aşamaları.

\subsubsection{Alan ve hacim hesaplamalart}

Alan ve hacim ölçümlerinin fotogrametri yazılımlarında uygulanması genellikle oluşturulan SAM ve SYM üzerinden yapılabilmektedir. Ancak bu çalışmada daha hassas ölçümler alınması için yoğun nokta bulutu üzerinden hareket edilecektir. Ölçüm için öncelikle sahanın taban sınırları belirlenmelidir. Bu sebepten, öncelikle sahanın çalışma için uygun yönteminin net olarak ortaya konması gerekmektedir [14].

Şekil 3'de görsellendiği gibi, taban sınırları net olarak görülen ve düz bir zeminde olan sahaların taban sınırları kolayca belirlenerek, yazılım içerisinde hacim ve alan ölçümü etkili bir şekilde yapılabilmektedir. $\mathrm{Bu}$ tarz alanlarda taban sinırları kolayca çizilebildiğinden, alınan hacim ve alan verileri de buna paralel olarak hassas olarak 
ortaya konabilmektedir. Taban ve üst yüzey belirlendikten sonra iki yüzey arasındaki hacim ve yüzey alanı neredeyse hatasız olarak hesaplanabilmektedir.

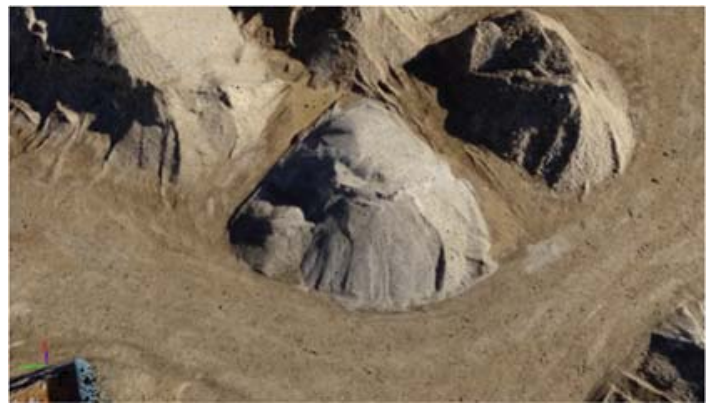

Şekil 3.Taban sınırları net görünen stok sahası örneği.

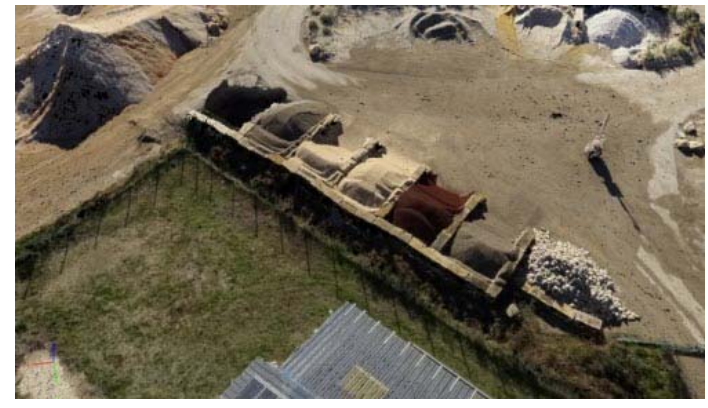

Şekil 4.Taban sınırları kısmen görünen stok sahası örneği.

Şekil 4'de gösterildiği gibi saha sınırlarının bir kısmı görünür diğer kısmı ise net olarak belirlenemeyen alanlarda, alan ve hacim ölçümü yapabilmek için yazılım içerisinde opsiyon olarak, taban kotunu sabitleme ya da yapılan çizime göre optimize etme işlemleri bulunmaktadır. Bu tarz sahalarda sınırlar, net olan yerler, normal olarak kalan kısımlar taban kotuna izdüşüm olarak optimize edilir. Böylece taban sınırları doğru şekilde belirlenebilir. Sonuç olarak, taban ve üst yüzeyin kesin olarak net bir biçimde belirlenmesi alan ve hacim ölçüm sistematiğinin öncelikli şartıdır.

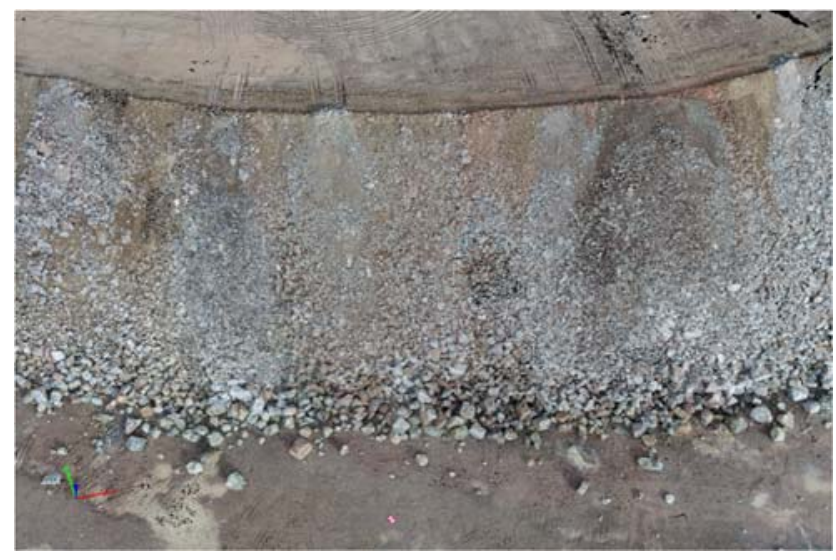

Şekil 5.Taban sınırları net olarak görünmeyen harfiyat sahası örneği.

Şekil 5'de görsellenen harfiyat alanı gibi, döküm yapılan alanlarda, döküm öncesine ait bilgi mevcut değil ise, taban sınırları gerçeğe yakın olarak çizilebilir. Bu durumda yapılan ölçüm tam net olmamakla birlikte, gerçekliği çok yüksek bir yaklaşım olarak kalır. Bu tarz durumlarda sahanın döküm öncesi ölçümü ve döküm sonrası ölçümü yapılarak, hassas bir şekilde alan ve hacim ölçümlerinin alınması çok daha gerçekçi sonuçlar verecektir.

\section{Saha çalışmaları ve bulgular}

Çalışma alanı şekil 6'da gösterildiği üzere İzmir/Bornova Laka köyü adresinde bulunan harfiyat sahasıdır. Alan çalışması iki aşamadan oluşmaktadır. Öncelikli olarak yerinde 
hacim ölçümü için belirlenen alanda kazı çalışması ve gevşemiş malzemenin hacmini ölçmek için döküm çalışmasıdır. İki alanda yapılan çalışmalar sonucunda elde edilen veriler birkaç gün süren işleme sürecinden geçmiştir. Veri işleme çalışmalarının tamamı İHA destekli fotogrametri yazılımında yapılmış ve başka herhangi bir ara yazılım kullanılmamıştır.

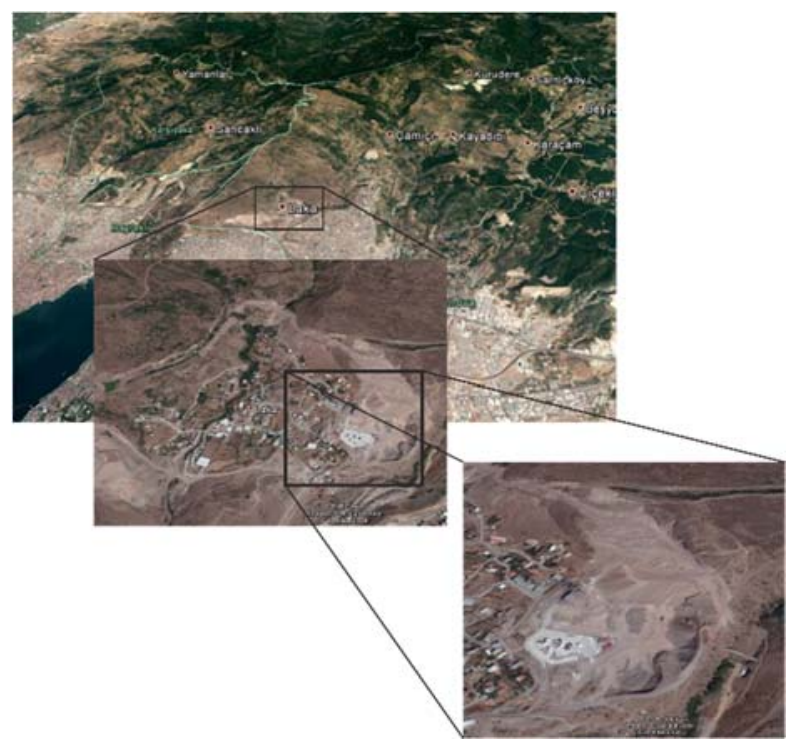

Şekil 6. Çalışma alanı lokasyonu (İzmir / Bornova).

\subsection{Kazı Çalışmaları}

Kazı alanı içerisinde özellikle düzensiz seçilmiş olan yaklaşık 10 x 8 metrelik bir alan iş makinaları yardımıyla kazılmıştır (Şekil 7). Kazı çalışması özellikle alan, hacim veya ağırlık vb. herhangi bir parametreye bağlı olarak yapılmamıştır.

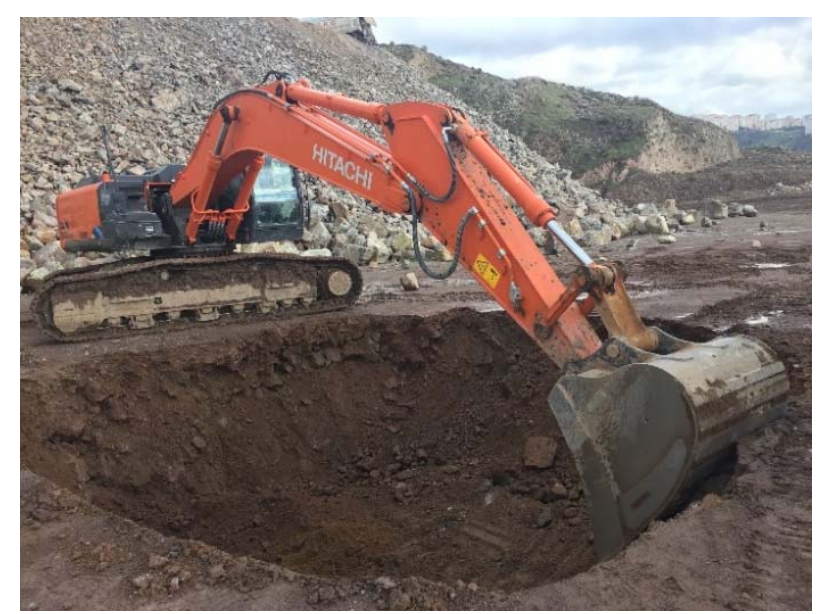

Şekil 7. Ölçümler için sahada yapılan kazı çalışması.

Kazı çalışması öncesinde İHA ile kısa süreli planlı otomatik ve manuel olmak üzere toplam iki uçuş, kazı sonrasında ise manuel olarak bir uçuş daha yapılmıştır. Şekil 8' de kazılmış alan, nokta bulutu olarak görsellenmiştir. Şekil 9'da ise kazılan alanın yan duvarlarından biri yine nokta bulutu üzerinden gösterilmiştir. Ayrıca sahada kazısı yaptırılan alan GNSS cihazı ile ölçülmüş ve Şekil 10'da ölçüm yapılan noktalar üçgenlemeleriyle birlikte verilmiştir. $\mathrm{Bu}$ işlem ölçüm ekibi tarafından kontrol amaçlı 
yapılmış olup, daha sonra karşılaştırma için kullanılacaktır. Şekil 11' de ise kazı alanının nokta bulutu görüntüsü, aşağıdan bakışla verilmektedir.

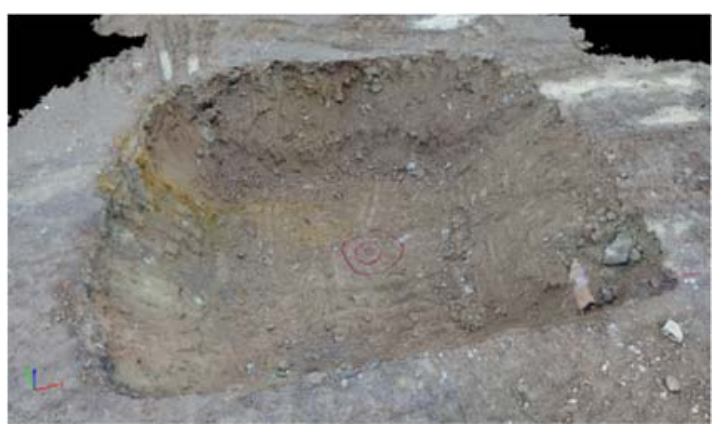

Şekil 8. Kazı alanı nokta bulutu görüntüsü.

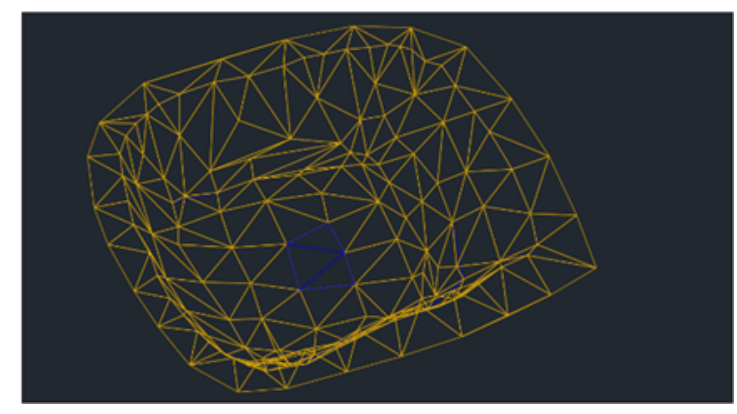

Şekil 10. Geleneksel Ölçüm methoduyla alınan noktalar ve üçgenlemeleri.

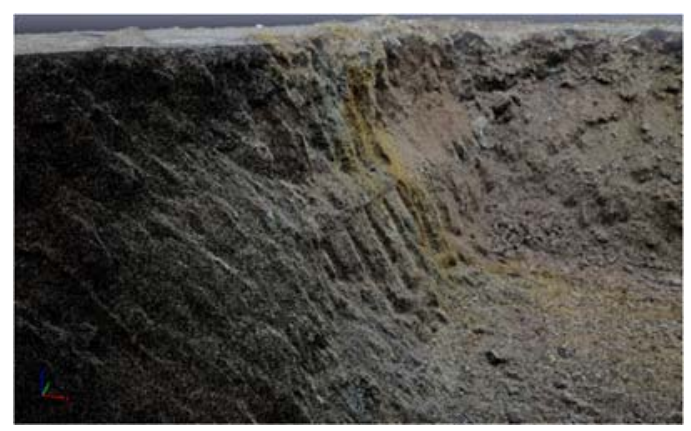

Şekil 9. Kazı alanı nokta bulutu görüntüsü (İçten).

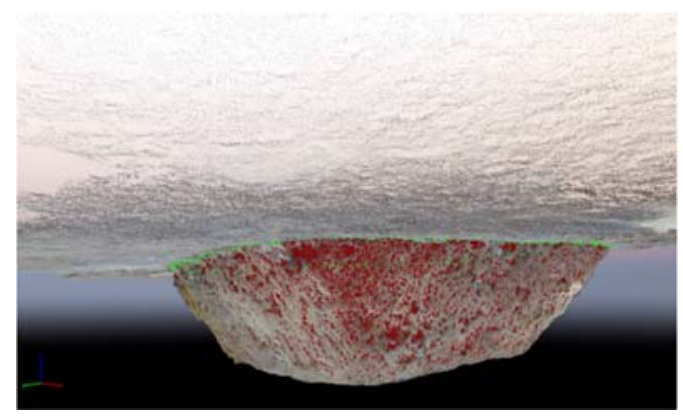

Şekil 11. IHA ile kazı alanı ölçümü üçgenleme aşamasının nokta bulutu üzerinden görüntüsü (alt görünüş).

\subsection{Döküm çalışmaları}

Kazı alanından boşaltılan hacmi yüklenerek çıkan kamyonlar, kantarda tartılarak, önceden belirlenen döküm alanına malzemenin dökümünü yapmıştır. Döküm öncesi ve sonrasında birer manuel uçuş yapılmış ve Şekil 12'de, döküm yapılacak alan nokta bulutu üzerinde gösterilmiştir (döküm öncesi). Şekil 13'de ise döküm sonrası alan, taban sinırları ile nokta bulutu üzerinde görsellenmiştir.

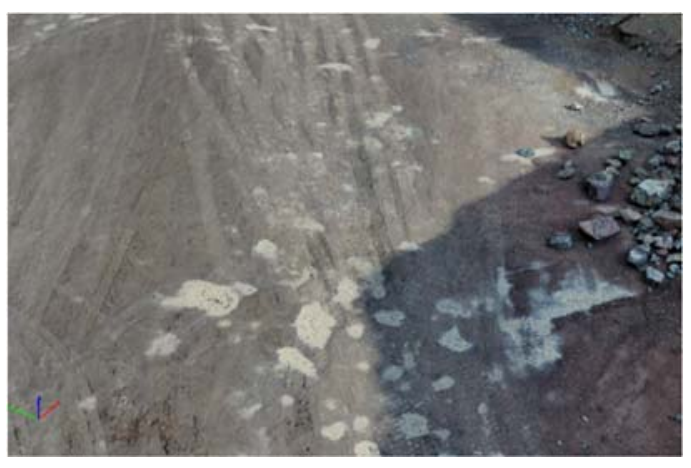

Şekil 12. Döküm alanı nokta bulutu görüntüsü.

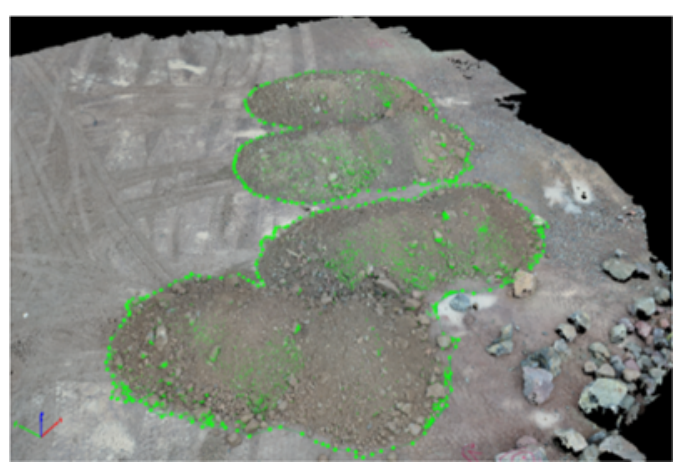

Şekil 13. Döküm sonrası, döküm alanı nokta bulutu görüntüsü. 
Kazı ve döküm alanında gerçekleştirilmiş olan dört nokta bulutu için ön bilgiler (kullanılan görsel ve nokta sayıları ile nokta yoğunlukları) tablo 2, tablo 3, tablo 4 ve tablo 5'te verilmiştir. Her bir işlem için 100 ile 450 arasında görsel kullanılarak yapılan çalışmada nokta yoğunlukları adet $/ \mathrm{m}^{3}$ olarak verilmektedir.

Tablo 2. Kazı öncesi uçuş için ön bilgi.

\begin{tabular}{|l|c|}
\hline Proje İsmi & Kazı Öncesi \\
\hline Kullanılan görsel sayısı & 439 \\
\hline Koordinatlı nokta sayısı & $\sim 55$ Milyon \\
\hline Nokta yoğunluğu & $6.859,27$ \\
\hline
\end{tabular}

Tablo 4. Döküm öncesi uçuş ön bilgi

\begin{tabular}{|l|c|}
\hline Proje İsmi & Kazı Öncesi \\
\hline Kullanılan görsel sayısı & 241 \\
\hline Koordinatlı nokta sayısı & $\sim 29$ Milyon \\
\hline Nokta yoğunluğu & $48.911,60$ \\
\hline
\end{tabular}

Tablo 3. Kazı sonrası uçuș için ön bilgi.

\begin{tabular}{|l|c|}
\hline Proje İsmi & Kazı Sonras1 \\
\hline Kullanılan görsel sayıs1 & 95 \\
\hline Koordinatlı nokta sayıs1 & $\sim 13$ Milyon \\
\hline Nokta yoğunluğu & $848.220,00$ \\
\hline
\end{tabular}

Tablo 5. Döküm sonrası uçuş ön bilgi

\begin{tabular}{|l|c|}
\hline Proje İsmi & Kazı Sonrası \\
\hline Kullanılan görsel sayısı & 287 \\
\hline Koordinatlı nokta sayısı & $\sim 42$ Milyon \\
\hline Nokta yoğunluğu & $669.509,00$ \\
\hline
\end{tabular}

Geleneksel ölçüm metodu ile (GNSS kullanımı ile) yapılan ölçüm sonrasında, kazı alanında Tablo 6' da verilen bilgiler elde edilmiştir. İki yöntemi kıyaslamak adına IHA ile elde edilen hesaplamalardan elde edilen sonuçlar da Tablo 6'de gösterilmektedir.

Tablo 6. Ölçüm sonuçlarının gösterimi.

\begin{tabular}{|l|c|c|}
\hline & $\begin{array}{l}\text { Geleneksel metodlar ile kazı } \\
\text { sonrası ölçüm sonuçları }\end{array}$ & $\begin{array}{l}\text { IHA ile yapılan ölçüm ve } \\
\text { hesaplama sonuçları }\end{array}$ \\
\hline Ölçülen Hacim $\left(\mathrm{m}^{3}\right)$ & 86,77 & 87,13 \\
\hline Hata Payı $\left(\mathrm{m}^{3}\right)$ & Belirtilmedi & $\pm 0,17$ \\
\hline $\begin{array}{l}\text { Koordinatlı nokta sayısı } \\
\text { (adet) }\end{array}$ & 262 & $\sim 12$ Milyon 675 Bin \\
\hline
\end{tabular}

\section{Sonuçlar ve tartışma}

İnsansız hava araçlarının (İHA) madencilik uygulamalarına dahil edilmesi ve kullanım potansiyelinin ortaya çıkarılması amacı ile hazırlanan çalışmada, açık işletme yoğunluklu olarak çalışan ülkemiz madencilik sektöründe, daha kısa sürelerde, daha hatasız ve daha pratik ölçüm ve buna bağlı olarak hesaplamaların yapılabilmesi amaçlanmıştır.

Çalışmada, insansız hava aracı ve uygun yazılım kullanımı ile; özellikle hacim, kütle, ve kabarma faktörü gibi kavramların, hesaplanması zor alanlarda, yerinde tespitine yönelik olarak çalışılmıştır. Maden işletmelerinde özellikle üretilen malzemenin nakliyesi sırasında yerinde belirlenmesi gereken bu parametrelerin, tam ve kesin olarak bilinmesi gerek makine ekipman seçimi gerekse maliyetlerin belirlenmesindeki rolü büyüktür. 
İHA destekli fotogrametri yazılımları ile yapılan ölçüm ve bilgisayar destekli hesaplamalar sonucunda, döküm alanı basamağında, rastantısal olarak yaklaşık 8x10x1 m. (en, boy, yükseklik) ebatlarında belirlenen kazı geometrisinin hacmi belirlenmeye çalışılmıştır.

İnsansız hava aracı kullanımı ile, 15-20 metreden alınan 100 adet koordinatlı görsel üzerinde yaklaşık 12 Milyon koordinatlı nokta kullanılarak belirlenen alandaki hacim $87.13 \mathrm{~m}^{3}$ olarak $\pm 0,17 \mathrm{~m}$. lik bir hata payı ile hesaplanmıştır. Aynı değer topograflar tarafından klasik metotlar kullanılarak (GNSS yardımı ile) yapılan ölçümler sonucunda $86,77 \mathrm{~m}^{3}$ olarak ölçülmüştür. Kazı işleminden sonra yapılan tartım ve kantar bilgileri de göz önüne alınarak (kazılan hacim 154.04 ton), ele alınan döküm alanı üzerindeki malzemenin yerindeki birim hacim ağırlı̆̆ yaklaşık 1,77 ton $/ \mathrm{m}^{3}$ olarak belirlenmiştir.

Benzer biçimde kazısı yapılan ve kazı hacmi belirlenen malzemenin, döküm alanındaki hacminin belirlenebilmesi için 287 adet koordinatlı görsel alımı yapılarak yaklaşı1 41 Milyon nokta üzerinde çalışılmıştır. Hesaplamalar sonucunda dökümün hacmi $89,11 \mathrm{~m}^{3}$ olarak elde edilmiştir. Buradan hareketle döküm alanından alınarak, yığın yapılan malzemenin kabarma faktörü (k) 1,02 olarak belirlenmiştir. Bu değer işletmeden işletmeye farklı formasyonların kendine has özellikleri nedeni ile değişeceğinden her işletme için ayrı ayrı belirlenmelidir.

Yukarda sayılan tüm çalışmalar iki ayrı uçuş planı ile yaklaşık bir saatlik toplam uçuş süresinde alınmıştır. Alınan koordinatlı görsellerin işlenmesi, düzenlenmesi ve yorumlanması işlemeleri de göz önüne alındığında ilksel sonuçlar 6-7 saat gibi kısa bir sürede ortaya konulmaktadır. Bu durum IHA lar ile yapılacak olan hesaplama ve ölçüm işlerinin güvenilirliğinin yanı sıra, hesaplamaların çok kısa sürede tamamlanabilmesi açısından da önemlidir.

Bunlardan bağımsız olarak, özellikle iş sağlığ 1 ve güvenliği gereksinimleri içerisinde, özellikle ulaşılması zor ve riskli olan alanlarda ölçümlerin bu denli hassas ve yüksek doğruluk payı ile alınabilmesi gerek insan gerekse işletme makine ekipman emniyet ve sağ lığı için vazgeçilmez bir unsurdur. Özellikle dünya ölçeğinde aktif ve hızla artan bir oranda kullanım alanı bulan İHA' ların ülkemizde de, giderek artan iş hacimleri ve özellikle açık maden sahalarının kontrolü göz önüne alındığında, ileriki yıllarda çok daha yaygın ve farklı amaçlar için kullanılacağı açıktır.

\section{Teșekkür}

Yazarlar, bu çalışmanın yapılmasında 2017.KB.FEN.021 nolu projeye olan desteği nedeni ile, DEU Bilimsel Araştırmalar Koordinatörlüğüne teşekkür eder.

\section{Kaynaklar}

[1] Öztürk, O., Bilgilioğlu, B.B., Çelik, F.M., Bilgilioğlu, S.S. ve Uluğ, R., İnsanız hava aracı (iha) görüntüleri ile ortogörüntü üretiminde yükseklik ve kamera açısının doğruluğa etkisinin araştırılması, Journal of Geomatics, 2(3),135-141, (2017).

[2] Niethammer, U., Rothmund, S. ve Joswig, M.,. UAV-based remote sensing of the lowmoving landslide Super-Sauze, Proceedings, International Conference 
on Landslide Processes, International Ass. from Geomorphologic Mapping to Dynamic Modelling CERG, 69-74, Strasbourg, (2009).

[3] Wing, M.G., Burnett, J., Johnson, S., Akay, A.E. ve Sessions, J., A low-cost unmanned aerial system for remote sensing of forested landscapes, International Journal of Remote Sensing Applications, 4(3), 113-120, (2014).

[4] Döner, F., Özdemir, S. ve Ceylan, M., Use of unmanned aircraft vehicle systems in data acquisition and mapping studies, Proceedings, $5^{\text {th }}$ Remote Sensing-GIS Symposium, 14-17 İstanbul, (2014).

[5] Mesas-Carrascosa, F.J., Notario-García, M.D., Larriva, J.E.M., Orden, M.S., ve Porras, A.G.F., Validation of measurements of land plot area using UAV imagery, International Journal of Applied Earth Observation and Geoinformation, 33, 270 - 279, (2014).

[6] Akgül, M., Yurtseven, H., Demir, M., Akay, A.E., Gülci, S. ve Öztürk, T., Production of high precision digital elevation model with unmanned aerial vehicles and use in forestry, Journal of the Faculty of Forestry, 66, 1,104-118, (2016).

[7] Yakar, M. ve Mirdan, Ö., Problems encountered in the modeling of historical monuments with unmanned aerial vehicle, Journal of Geomatics, 2(3), 118125, (2017).

[8] Sarı, H ve Özcan, O., Determining the spatial effects of quarries using a drone: the case of the Süleymanpaşa-Tekirdağ quarries, Fresenius Environmental Bulletin, 28, 1, 53-61, (2019).

[9] Gül, Y., Açık maden işletmelerinde insansız hava aracı (İHA) uygulamaları, Türkiye Jeoloji Bülteni, 62, 99-112, (2019).

[10] https://www.dji.com/phantom-4-pro/info, (01.10.2018).

[11] https://www. iha.sghm.gov.tr, (01.10.2017).

[12] http://geoconnect.com.au/spectra-precision-promark-800/, (01.11.2018).

[13] Kim, J.O., ve Lee, J.K., UAV application for process control of the reclamation, Proceedings, $2^{\text {nd }}$ International Water Safety Symposium Journal of Coastal Research, 309-313, Florida, (2017).

[14] https://support.pix4d.com/hc/en-us/articles/217114246, (12.10.2017). 